\title{
First-principles modeling of the infrared spectrum of Fe- and Al-bearing lizardite
}

\author{
Etienne Balan ${ }^{1}$, Emmanuel Fritsch ${ }^{1,2}$, Guillaume Radtke ${ }^{1}$, Lorenzo Paulatto ${ }^{1}$, Farid Juillot ${ }^{1,2}$, \\ Fabien Baron ${ }^{3}$, and Sabine Petit $^{3}$ \\ ${ }^{1}$ Sorbonne Université, CNRS, MNHN, Institut de Minéralogie, de Physique des Matériaux et de Cosmochimie \\ (IMPMC), 4 place Jussieu, 75252 Paris CEDEX 05, France \\ ${ }^{2}$ Institut de Recherche pour le Développement (IRD), Centre de Nouméa, 101 Promenade Roger Laroque, \\ Anse Vata, 98848 Nouméa, New Caledonia \\ ${ }^{3}$ Institut de Chimie des Milieux et Matériaux de Poitiers (IC2MP), CNRS UMR 7285, \\ Université de Poitiers, 6 rue Michel Brunet, 86073, Poitiers CEDEX 9, France
}

Correspondence: Etienne Balan (etienne.balan@sorbonne-universite.fr)

Received: 6 July 2021 - Revised: 21 September 2021 - Accepted: 30 September 2021 - Published: 27 October 2021

\begin{abstract}
The theoretical vibrational properties of a series of Fe- and Al-bearing lizardite models have been determined at the density functional theory level. Each periodic model displays a single cationic impurity substituted at an octahedral or tetrahedral site of a supercell of lizardite $\left(\mathrm{Mg}_{3} \mathrm{Si}_{2} \mathrm{O}_{5}(\mathrm{OH})_{4}\right)$ containing 162 atoms. The isovalent $\mathrm{Fe}^{2+}$ for $\mathrm{Mg}^{2+}$ substitution has been considered, as well as the heterovalent substitution of $\mathrm{Fe}^{3+}$ or $\mathrm{Al}^{3+}$ for $\mathrm{Mg}^{2+}$ or $\mathrm{Si}^{4+}$. Comparison of the theoretical absorption spectra with previously reported experimental spectra of natural and laboratory-grown lizardite samples allows us to propose an interpretation for most of the observed bands. Although the identification of specific bands related to octahedral $\mathrm{Fe}^{2+}$ in FTIR spectra is challenging, broad bands at 3584 and $3566 \mathrm{~cm}^{-1}$ reflect the occurrence of octahedral $\mathrm{Al}^{3+}$ and $\mathrm{Fe}^{3+}$, respectively, in the natural samples. These broad bands likely overlap with potential contribution related to tetrahedral $\mathrm{Al}^{3+}$. It is suggested that the modification of the H-bonding pattern related to the incorporation of trivalent ions at tetrahedral sites has an overall broadening effect on the interlayer-OH stretching bands of lizardite.
\end{abstract}

\section{Introduction}

The stretching vibrations of $\mathrm{OH}$ groups are widely used to probe the local order of hydrous phyllosilicates. Applications range from the determination of the stacking pattern in clay minerals (e.g., Brindley et al., 1986; Prost et al., 1989; Fialips et al., 2001) to the analysis of cationic ordering in solid solutions (e.g. Petit et al., 2004; Baron and Petit, 2016) and to the study of structural phase transitions as a function of pressure (e.g., Johnston et al., 2002; Welch et al., 2012). The small mass of hydrogen leads to frequencies significantly higher than those of other vibrational modes, whereas their relative variations as a function of macroscopic or microscopic perturbations usually do not exceed a few percents. These properties facilitate the identification of the corresponding vibrational spectroscopic signals, most often in the $3000-3700 \mathrm{~cm}^{-1}$ range (e.g., Farmer, 1974; Szalay et al.,
2002). In addition, the high frequency and weak dispersion of these "hard modes" result in a localized character (e.g., Salje, 1992), which supports the interpretation of observed spectroscopic changes in terms of modifications of the local atomic-scale environment of $\mathrm{OH}$ groups.

The stretching frequencies of $\mathrm{OH}$ groups are dominantly controlled by the strength of $\mathrm{H}$ bonding and by the nature of the neighboring cations (e.g., Farmer, 1974; Hermansson, 1991; Libowitsky, 1999). In trioctahedral phyllosilicates, specific bands involving the structural $\mathrm{OH}$ groups located between the octahedral and tetrahedral sheets of the layers (inner-OH groups) have been unambiguously related to isovalent cationic substitutions in the coordination sphere of the oxygen atom (Petit et al., 2004; Blanchard et al., 2018). The effect of cationic substitutions on interlayer-OH groups, located on the outer side of the octahedral sheets of $1: 1$ 
phyllosilicates and pointing in their interlayer spacing, is less clearly established. In this case, the $\mathrm{OH}$ stretching modes can involve the coupled motion of the different interlayer$\mathrm{OH}$ groups occurring in the mineral unit cell, leading to a 10 to $20 \mathrm{~cm}^{-1}$ splitting of interlayer-OH modes. The local perturbation of $\mathrm{OH}$ vibrations by neighboring cationic substitutions (typically $14 \mathrm{~cm}^{-1}$ for a $\mathrm{Fe}^{2+}$ or $\mathrm{Ni}^{2+}$ for $\mathrm{Mg}^{2+}$ substitution at octahedral sites; Petit et al., 2004) is thus of similar magnitude than the effect of the coupling between the interlayer-OH groups. Furthermore, the potential occurrence of multivalent elements, such as iron, the simultaneous substitution at octahedral and tetrahedral sites by trivalent cations (e.g., Serna et al., 1979), and variations of the cationic ordering and potential intermediate di-tri-octahedral character of extended solid solutions (Bailey, 1988) may affect the interpretation of the vibrational spectra of chemically complex synthetic or natural samples. This is particularly true for the serpentine-group minerals, which can display significant variations of their chemical composition, with a frequent departing from the ideal $\mathrm{Mg}_{3} \mathrm{Si}_{2} \mathrm{O}_{5}(\mathrm{OH})_{4}$ formula related to the occurrence of iron and aluminum (e.g., Viti and Mellini, 1997). These elements can play an important role in serpentine-group minerals because the interplay of chemical composition, electrostatic interactions and structural strain has been suggested as a potential control of the layer curvature, driving the growth of the planar lizardite vs. tubular chrysotile variety (e.g., Mellini, 1982; Wicks and O'Hanley, 1988; Viti and Mellini, 1997). The presence of aluminum has also been shown to significantly affect the chemical reactivity of serpentine minerals (Lacinska et al., 2016).

In the present study, we theoretically investigate the effect of $\mathrm{Fe}$ and $\mathrm{Al}$ substitutions at low concentration on the vibrational and infrared absorption properties of lizardite, the more symmetric planar member of serpentine-group minerals. The theoretical calculation of the IR spectrum of $\mathrm{Fe}^{2+}$ , $\mathrm{Fe}^{3+}$ - and $\mathrm{Al}^{3+}$-bearing lizardite supports the assignment of some features of the experimental spectra of serpentinegroup minerals to site-specific substitutions and sheds light on the inhomogeneous broadening mechanisms of the other vibrational bands related to cationic substitutions. Although the focus is on the OH stretching modes, the effect of substitutions on the lower-frequency region of the spectra is also discussed.

\section{Methods}

The theoretical modeling framework is the same as that previously used for investigating the structural and vibrational properties of other phyllosilicates and hydrous minerals (e.g., Balan et al., 2001, 2002). Relevant properties were obtained using density functional theory (DFT) with the generalized gradient approximation (GGA) for the exchange-correlation functional (xc-functional) as proposed by Perdew, Burke, and Ernzerhof (PBE) (Perdew et al., 1996) and a plane- wave/pseudo-potential scheme, as implemented in the PWscf and PHonon codes from the Quantum ESPRESSO package (Giannozzi et al., 2009; http://www.quantum-espresso.org, last access: 23 October 2021). The ionic cores were described by optimized norm-conserving pseudo-potentials from the SG15-ONCV library (Hamman, 2013; Schlipf and Gigy, 2015). The wave functions and the charge density were expanded in plane waves with 80 and 480 Ry cutoffs, respectively, as in previous studies (e.g., Balan et al., 2021b).

Structural properties of $\mathrm{Fe}$ - and Al-bearing lizardite were determined using $3 \times 3 \times 1$ lizardite supercells $(162$ atoms) containing one cationic impurity substituting an octahedrally coordinated $\mathrm{Mg}^{2+}$ cation or a tetrahedrally coordinated $\mathrm{Si}^{4+}$ cation. The chemical composition of the corresponding system is $\left(\mathrm{Mg}_{1-x} \mathrm{X}_{x}\right)_{3} \mathrm{Si}_{2} \mathrm{O}_{5}(\mathrm{OH})_{4}$ or $\mathrm{Mg}_{3}\left(\mathrm{Si}_{1-x} \mathrm{X}_{x}\right)_{2} \mathrm{O}_{5}(\mathrm{OH})_{4}$, where $\mathrm{X}$ is the impurity and $x=$ 0.037 or 0.055 for a substitution at the octahedral (M) or tetrahedral $(\mathrm{T})$ site, respectively. These systems differ from those investigated by Scholtzová and Smrčok (2005), who considered the structural effect of coupled substitutions by trivalent cations at both $\mathrm{M}$ and $\mathrm{T}$ sites, which would make it difficult to disentangle each individual effect on vibrational properties. Given the supercell size, the Brillouin zone sampling for electronic integration was restricted to a $1 \times 1 \times 2$ k-point grid. The unit-cell parameters of pure lizardite- $1 T$ were optimized at zero pressure and then used without further relaxation to produce the Fe- and Al-bearing supercells. Reduced atomic coordinates were relaxed until the residual forces on atoms were less than $10^{-4}$ Ry/a.u. For the models displaying heterovalent substitutions, a compensating homogeneous electrostatic background was spread over the supercell to ensure the macroscopic neutrality of the periodic system. This electrostatic correction avoids the divergence of the system total energy but is not expected to significantly affect the microscopic vibrational properties of ionic systems (e.g., Leslie and Gillan, 1985). Spin-polarized calculations were performed on $\mathrm{Fe}^{2+}$ - and $\mathrm{Fe}^{3+}$-bearing systems, imposing the high-spin state of the isolated paramagnetic ion to the supercell.

Harmonic vibrational (displacements and frequencies of the 486 normal vibrational modes at the Brillouin zone center) and dielectric (Born effective charge tensors and electronic dielectric tensor) properties were calculated from the second-order derivatives of the total energy with respect to atomic displacements and external electric field using the linear response theory (Baroni et al., 2001). The theoretical powder infrared absorption spectra were obtained from the low-frequency dielectric tensor using the approach developed by Balan et al. (2001, 2008). This approach computes the orientational average of the electromagnetic power dissipated in an ellipsoidal particle inserted in an infinite isotropic matrix, which is characterized by a real dielectric constant, assuming that the isolated particle has a size significantly smaller than the IR wavelength. The absorption is equivalent to that of a Maxwell Garnet effective medium in the 
high-dilution limit (Kendrick and Burnett, 2016). In the calculation of the low-frequency dielectric tensor (Balan et al., 2001), a damping coefficient of $2 \mathrm{~cm}^{-1}$ was arbitrarily used to account for the homogeneous width of absorption bands.

\section{Results}

\subsection{Theoretical properties of pure lizardite}

The unit-cell parameters of lizardite-1T (S.G. P31m) $(a=$ $b=5.37 \AA, c=7.36 \AA$ ) compare well with previous values obtained at the same theoretical level (e.g., Prencipe et al., 2009; Hossain et al., 2001; Adebayo et al., 2011; Tunega et al., 2012; Ghaderi et al., 2015). As usually observed in DFT modeling performed at the GGA level, they are overestimated with respect to their experimental counterparts (e.g., $a=b=5.3267 \AA$ А, $c=7.2539 \AA$; Gregorkiewitz et al., 1996). Each layer of the structure contains a pseudo-hexagonal silica sheet of corner-shared $\mathrm{SiO}_{4}$ units linked to a trioctahedral sheet of edge-sharing $\mathrm{MgO}_{2}(\mathrm{OH})_{4}$ octahedra. Selected theoretical lengths of cation oxygen bonds (Table 1) are in good agreement with the experimental findings and consistent with previous theoretical calculations (Balan et al., 2002; Prencipe et al., 2009). The $\mathrm{Mg}-\mathrm{O}(\mathrm{Si})$ distance is the longest $\mathrm{Mg}-\mathrm{O}$ distance, and the apical $\mathrm{Si}-\mathrm{O}$ bonds are shorter than the equatorial ones. The interlayer-OH bonds is longer than the inner-OH bond by $0.004 \AA$. The theoretical magnitude of the ditrigonal distortion $\left(\alpha=-4.1^{\circ}\right)$ is slightly overestimated with respect to the experimental value of $-2.6^{\circ}$ (Gregorkiewitz et al., 1996).

Vibrational properties of lizardite (Table 2) are consistent with those previously determined (Balan et al., 2002; Prencipe et al., 2009). Note however that the theoretical frequencies slightly differ from those of Balan et al. (2002) due to the full relaxation of the unit cell in the present study and use of different pseudo-potentials. The inner$\mathrm{OH}$ stretching mode leads to a weak absorption band at $3783 \mathrm{~cm}^{-1}$ (Fig. 1). The transverse optical (TO) frequency of the in-phase stretching mode ( $A_{1}$ symmetry) of interlayer$\mathrm{OH}$ groups is calculated at $3721 \mathrm{~cm}^{-1}$ (Table 2) and leads to an absorption band at $3740 \mathrm{~cm}^{-1}$ in the spectrum computed for a (001) platy particle shape (Fig. 1). For a mode polarization along the [001] direction, this higher frequency coincides with the longitudinal optical (LO) frequency of the mode (Balan et al., 2005), indicating a LO-TO splitting of $19 \mathrm{~cm}^{-1}$. This value compares well with those previously determined $\left(21 \mathrm{~cm}^{-1}\right.$, Balan et al., $2002 ; 14 \mathrm{~cm}^{-1}$, Prencipe et al., 2009). The degenerate out-of-phase stretching mode (E symmetry) of interlayer-OH groups is calculated at $3704 \mathrm{~cm}^{-1}$ (Table 1).

At lower frequency (Fig. 2), the stretching modes involving apical or equatorial $\mathrm{Si}-\mathrm{O}$ bonds correspond to absorption bands at 1062 and $880 \mathrm{~cm}^{-1}$, respectively, with the former being calculated at the LO frequency because of the

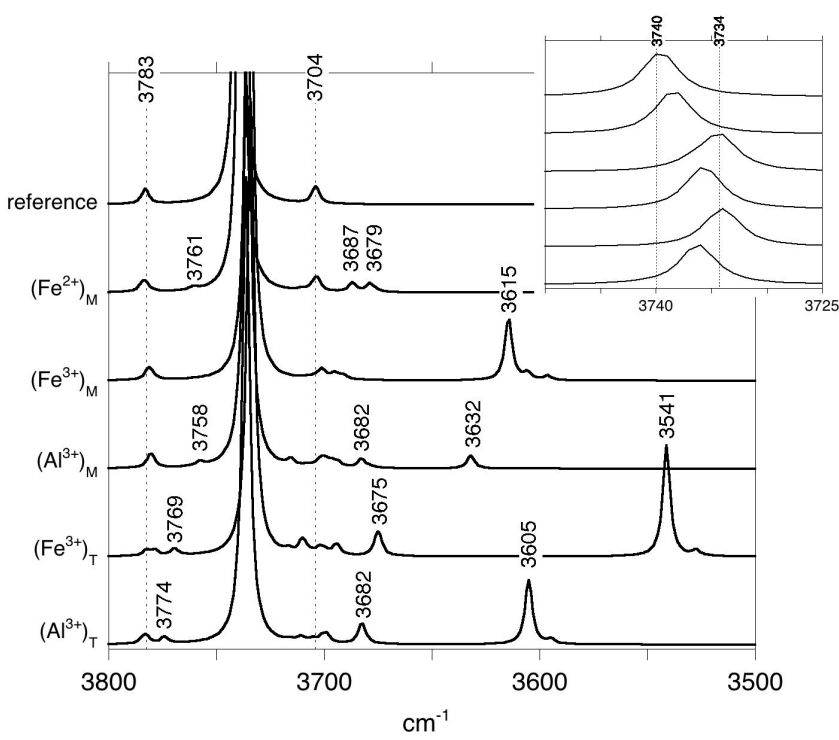

Figure 1. Theoretical absorbance spectra in the $\mathrm{OH}$ stretching region of the Fe- and Al-bearing lizardite models. The reference spectrum corresponds to pure lizardite. The spectra have been computed for a platy particle inserted in a $\mathrm{KBr}$ medium $\left(\varepsilon_{\mathrm{KBr}}=2.25\right)$. Due to electrostatic effects, the position of absorption bands can differ from the TO mode frequencies reported in Table 2 (see text). Inset: enlarged view of the main band related to the stretching of interlayer$\mathrm{OH}$ groups in lizardite. The presence of cationic impurities leads to a moderate shift and broadening of this band.

platy morphology of the particle (Balan et al., 2002). The bands at 643,607 and $590 \mathrm{~cm}^{-1}$ correspond to the libration of interlayer- $\mathrm{OH}$ groups, the libration of inner- $\mathrm{OH}$ group and the hindered translation in the [001] direction of interlayer$\mathrm{OH}$ groups, respectively. The bands at 422 and $401 \mathrm{~cm}^{-1}$ correspond to more complex displacement patterns involving the interlayer- $\mathrm{OH}$ groups and contributions of $\mathrm{Mg}$ and $\mathrm{Si}$ cations. Finally, the band at $274 \mathrm{~cm}^{-1}$ involves a collective atomic motion corresponding to an internal shearing of the layers parallel to the (001) plane.

\subsection{Theoretical properties of $\mathrm{Fe}^{2+}$-bearing lizardite $\left(\left(\mathrm{Fe}^{2+}\right)_{\mathrm{M}}\right.$ model $)$}

Cationic substitution at the octahedral site reduces the $3 m$ symmetry of the system to a mirror symmetry. The average $\mathrm{Fe}^{2+}$ oxygen bond length increases from 2.09 to $2.13 \AA$ due to the slightly larger ionic radius of $\mathrm{Fe}^{2+}(0.78 \AA)$ compared to that of $\mathrm{Mg}^{2+}(0.72 \AA)$ (Shannon, 1976). The length of inner- $\mathrm{OH}(\mathrm{OH} 4)$ and interlayer- $\mathrm{OH}(\mathrm{OH} 3)$ groups increases by 0.001 to $0.002 \AA$ with respect to those in pure lizardite (Table 1). The three interlayer-OH groups linked to the substituting cation are not equivalent. The interlayer$\mathrm{OH}$ group located on the mirror plane (noted $\mathrm{OH}_{\mathrm{m}}$ ) can be distinguished from the two other $\mathrm{OH}$ groups (noted $\mathrm{OH}_{\mathrm{e}}$ ), which are symmetrically equivalent by mirror operation. In 
Table 1. Selected theoretical bond lengths ( $\mathrm{A})$ in pure and Fe- and Al-bearing lizardite. The interlayer and inner $\mathrm{OH}$ correspond to $\mathrm{OH} 3$ and $\mathrm{OH} 4$, respectively.

\begin{tabular}{lrrrrrr}
\hline & & & & & & \\
& Lizardite & $\left(\mathrm{Fe}^{2+}\right)_{\mathrm{M}}$ & $\left(\mathrm{Fe}^{3+}\right)_{\mathrm{M}}$ & $\left(\mathrm{Al}^{3+}\right)_{\mathrm{M}}$ & $\left(\mathrm{Fe}^{3+}\right)_{\mathrm{T}}$ & $\left(\mathrm{Al}^{3+}\right)_{\mathrm{T}}$ \\
\hline $\mathrm{OH} 3$ & 0.967 & $0.968^{\mathrm{a}}, 0.969 \times 2^{\mathrm{b}}$ & 0.974 & $0.972^{\mathrm{a}}, 0.970 \times 2^{\mathrm{b}}$ & 0.976 & 0.973 \\
$\mathrm{OH} 4$ & 0.963 & 0.964 & 0.967 & 0.965 & 0.964 & 0.964 \\
$\mathrm{M}-\mathrm{O}(\mathrm{Si}) \times 2$ & 2.16 & 2.22 & 2.11 & 1.98 & - & - \\
$\mathrm{M}-\mathrm{O}(\mathrm{H} 4)$ & 2.10 & 2.16 & 2.05 & 1.92 & - & - \\
$\mathrm{M}-\mathrm{O}(\mathrm{H} 3) \times 3$ & 2.04 & $2.08,2.07 \times 2$ & $1.99,2.00 \times 2$ & $1.89,1.90 \times 2$ & - & - \\
$\mathrm{T}-\mathrm{O}_{\text {apical }}$ & 1.61 & - & - & - & 1.81 & 1.73 \\
$\mathrm{~T}-\mathrm{O}_{\text {basal }}$ & 1.67 & - & - & - & 1.90 & 1.78 \\
\hline
\end{tabular}

${ }^{\mathrm{a}} \mathrm{OH}_{\mathrm{m}} \cdot{ }^{\mathrm{b}} \mathrm{OH}_{\mathrm{e}}$.

Table 2. Theoretical transverse optical (TO) OH stretching frequencies $\left(\mathrm{cm}^{-1}\right)$ in pure and Al- and Fe-bearing lizardite. The frequencies reported for $\mathrm{Mg}_{3} \mathrm{OH}$ in the substituted models correspond to the main band associated with an in-phase motion of the OH groups and to IRactive modes displaying out-of-phase displacement patterns. Depending on the system, the intensity of the latter can be spread over several modes in the specified frequency range.

\begin{tabular}{lrrrrrr}
\hline & Lizardite & $\left(\mathrm{Fe}^{2+}\right)_{\mathrm{M}}$ & $\left(\mathrm{Fe}^{3+}\right)_{\mathrm{M}}$ & $\left(\mathrm{Al}^{3+}\right)_{\mathrm{M}}$ & $\left(\mathrm{Fe}^{3+}\right)_{\mathrm{T}}$ & $\left(\mathrm{Al}^{3+}\right)_{\mathrm{T}}$ \\
\hline Inner $\mathrm{Mg}_{3}-\mathrm{OH}$ & 3783 & 3783 & 3781 & 3780 & 3782 & 3783 \\
\hline Inner $\mathrm{OH}$ & & 3761 & 3736 & 3758 & 3769 & 3774 \\
\hline Interlayer $\mathrm{Mg}_{3}-\mathrm{OH}$ & 3721 & 3720 & 3717 & 3719 & 3720 & 3720 \\
& 3704 & 3703 & $3691-3713$ & $3693-3717$ & $3674-3718$ & $3681-3717$ \\
\hline Interlayer $\mathrm{OH}$ & & 3686 & 3612 & 3682 & 3536 & 3602 \\
& & 3678 & 3606 & 3679 & $3527 \times 2$ & $3595 \times 2$ \\
& 3676 & 3596 & 3631 & & \\
\hline
\end{tabular}

the $\mathrm{Fe}^{2+}$-bearing system, the $\mathrm{OH}_{\mathrm{m}}$ is $0.001 \AA$ shorter than the two $\mathrm{OH}_{\mathrm{e}}$ groups.

These local structural changes affect the vibrational properties. The presence of a $\mathrm{Fe}^{2+}$ cation in the coordination sphere of the inner-OH group shifts its vibrational frequency from 3783 to $3761 \mathrm{~cm}^{-1}$ (Table 2). The Born effective charge tensor of hydrogen is also affected, and the IR absorption coefficient of the corresponding $\mathrm{OH}$ stretching band increases by $33 \%$ with respect to that in pure lizardite. The stretching modes related to the interlayer-OH groups are also shifted at lower frequency with respect to the interlayer stretching modes of pure lizardite (Table 2). Due to the symmetry reduction, the mode at $3686 \mathrm{~cm}^{-1}$ is dominantly related to the shorter $\mathrm{OH}_{\mathrm{m}}$ bond, whereas the mode at $3676 \mathrm{~cm}^{-1}$ involves the out-of-phase stretching of the two other $\mathrm{OH}_{\mathrm{e}}$ groups. The intermediate mode at $3678 \mathrm{~cm}^{-1}$ combines the in-phase stretching of the $\mathrm{OH}_{\mathrm{e}}$ groups with an out-of-phase motion of the $\mathrm{OH}_{\mathrm{m}}$ group. Compared with the splitting of interlayer$\mathrm{OH}$ stretching modes of $\mathrm{A}_{1}$ and $\mathrm{E}$ symmetry in pure lizardite $\left(\sim 20 \mathrm{~cm}^{-1}\right)$, the frequency splitting of the $\mathrm{OH}$ modes associated with the substitutional defect is reduced to less than $10 \mathrm{~cm}^{-1}$.
The effect of the substituting $\mathrm{Fe}^{2+}$ cation on the stretching frequency of the bands related to the other more distant $\mathrm{OH}$ groups, which are only linked to $\mathrm{Mg}$ cations, does not exceed $1 \mathrm{~cm}^{-1}$ (Fig. 1). The presence of $\mathrm{Fe}^{2+}$ has a weak effect on the other vibrational modes of the system (Fig. 2), which is consistent with the limited structural distortion of the octahedral sheet induced by the impurity, also previously reported by Scholtzová and Smrčok (2005). A $3 \mathrm{~cm}^{-1}$ splitting of the band related to the basal $\mathrm{Si}-\mathrm{O}$ stretching mode leads to a shoulder at $877 \mathrm{~cm}^{-1}$ (not visible on Fig. 2). A more significant change affects the collective mode at $274 \mathrm{~cm}^{-1}$, which is split and downshifted to $264 \mathrm{~cm}^{-1}$. This suggests that the opposite shift reported by Baron and Petit (2016) as a function of $\mathrm{Ni}$ concentration in the lizardite-népouite series is predominantly due to the decrease in the system molar volume. This effect is not accounted for by the present modeling approach, which aims at determining the properties of defective systems in the high dilution limit. Weak additional bands related to a modification of the $\mathrm{OH}$ libration modes are observed in the $630-670 \mathrm{~cm}^{-1}$ range. 


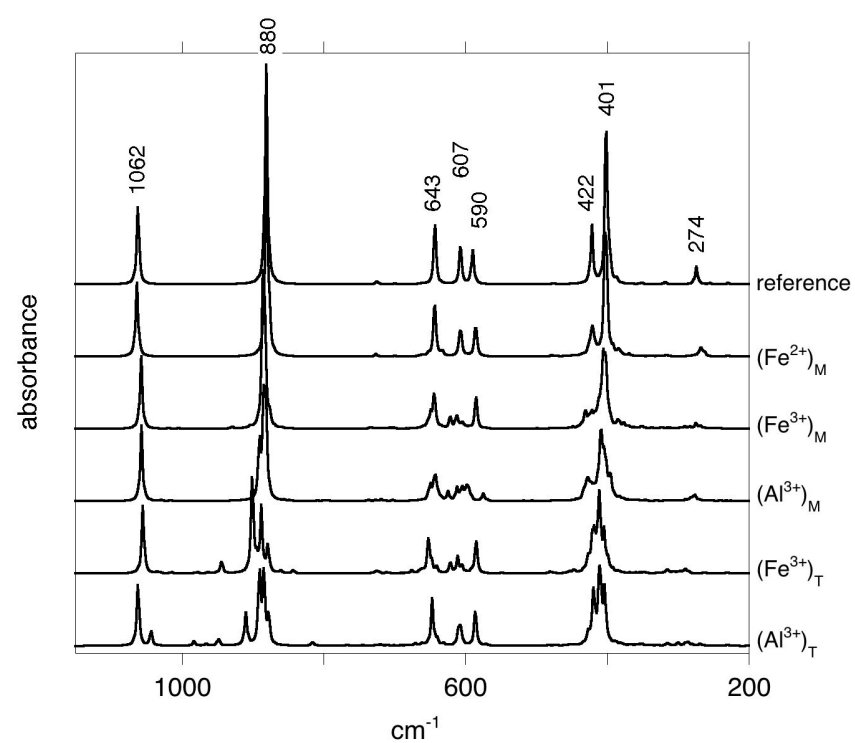

Figure 2. Theoretical absorbance spectra in the mid-infrared region of the Fe- and Al-bearing lizardite models. The reference spectrum corresponds to pure lizardite. The spectra have been computed as in Fig. 1. Note the very small modifications related to the occurrence of $\mathrm{Fe}^{2+}$ ions in the octahedral site.

\subsection{Theoretical properties of $\mathrm{Fe}^{3+}$ - and $\mathrm{Al}^{3+}$-bearing lizardite}

\subsubsection{Trivalent cations at octahedral sites $\left(\left(\mathrm{Fe}^{3+}\right)_{\mathrm{M}}\right.$ and $\left(\mathrm{Al}^{3+}\right)_{\mathrm{M}}$ models)}

The occurrence of trivalent $\mathrm{Fe}^{3+}$ and $\mathrm{Al}^{3+}$ cations at octahedral sites also reduces the system symmetry from $3 m$ to $m$. The shortening of cation-oxygen bond lengths and contraction of the substituted site are stronger for $\mathrm{Al}^{3+}$ than for $\mathrm{Fe}^{3+}$, as expected from their respective ionic radii $\left(\mathrm{Fe}^{3+}\right.$ : $0.645 \AA, \mathrm{Al}^{3+}: 0.535 \AA$ ), which are both significantly smaller than that of the octahedrally coordinated $\mathrm{Mg}^{2+}$ ion $(0.72 \AA)$ (Shannon, 1976).

The presence of a trivalent cation affects the $\mathrm{OH}$ groups belonging to its coordination sphere. The lengthening of the inner-OH $(\mathrm{OH} 4)$ bonds by 0.003 and $0.002 \AA$ (Table 1) downshifts their stretching frequency by 47 and $25 \mathrm{~cm}^{-1}$ for $\mathrm{Fe}^{3+}$ and $\mathrm{Al}^{3+}$ cations, respectively. A significant lengthening of interlayer- $\mathrm{OH}_{\mathrm{m}}$ and $\mathrm{OH}_{\mathrm{e}}$ bonds is also observed $\left(0.007 \AA\right.$ for $\mathrm{Fe}^{3+}, 0.004 \AA$ for $\left.\mathrm{Al}^{3+}\right)$. For the $\mathrm{Fe}^{3+}$-bearing system, the three interlayer-OH bonds have a similar length despite the lowering of the site symmetry (Table 1). Their coupling leads to three modes respectively computed at $3612 \mathrm{~cm}^{-1}$ for the in-phase motion of the three groups and at 3606 and $3596 \mathrm{~cm}^{-1}$ for their out-of-phase motion (Table 2). A different vibrational pattern is observed for the $\mathrm{Al}^{3+}$-bearing system. In this case, the stronger distortion of the octahedral site induces a more significant difference in the length of the interlayer-OH bonds. The longer $\mathrm{OH}_{\mathrm{m}}$ bond leads to a mode at $3631 \mathrm{~cm}^{-1}$ (Table 2). The two other modes at 3682 and $3679 \mathrm{~cm}^{-1}$ correspond to the in-phase and outof-phase motion of the $\mathrm{OH}_{\mathrm{e}}$ groups, respectively (Table 2).

Compared to the $\mathrm{Fe}^{2+}$-bearing system that mostly show local perturbation of vibrational properties, the presence of octahedrally coordinated trivalent cations has a more significant effect on the vibrational spectrum of lizardite because the perturbation extends toward more distant atoms. The main interlayer-OH stretching band is downshifted by 4 to $6 \mathrm{~cm}^{-1}$, whereas several resonances involving out-of-phase displacement patterns appear in the $3691-3717 \mathrm{~cm}^{-1}$ range (Fig. 1). The apical $\mathrm{Si}-\mathrm{O}$ stretching band is downshifted by $\sim 9 \mathrm{~cm}^{-1}$, whereas the equatorial stretching modes are split and the main band is upshifted by $\sim 5 \mathrm{~cm}^{-1}$. In the $\mathrm{Al}^{3+}$. bearing system, the splitting of the equatorial $\mathrm{Si}-\mathrm{O}$ modes is stronger than in the $\mathrm{Fe}^{3+}$-bearing system, reaching $7 \mathrm{~cm}^{-1}$ (Fig. 2). For both systems, the $\mathrm{OH}$ libration and hindered translation modes are significantly affected. The splitting of vibrational modes to a significantly higher number of IR active modes tends to spread the IR absorption over a range of frequencies (Fig. 2), inducing a complex broadening of the signals in the $560-660 \mathrm{~cm}^{-1}$ range.

\subsubsection{Trivalent cations at tetrahedral sites $\left(\left(\mathrm{Fe}^{3+}\right)_{\mathrm{T}}\right.$ and $\left(\mathrm{Al}^{3+}\right)_{\mathrm{T}}$ models)}

The substitution of larger $\mathrm{Al}^{3+}$ and $\mathrm{Fe}^{3+}$ for $\mathrm{Si}^{4+}$ cations preserves the 3 -fold symmetry of the tetrahedral site. It has a significant effect on the cation-oxygen bond lengths, which increase from 1.61 to 1.73 and $1.81 \AA$ for the apical $\mathrm{T}-\mathrm{O}$ bond and from 1.67 to 1.78 and $1.90 \AA$ for the basal $\mathrm{T}-\mathrm{O}$ bond for $\mathrm{Al}^{3+}$ and $\mathrm{Fe}^{3+}$, respectively (Table 1). Due to the relative stiffness of the $\mathrm{T}-\mathrm{O}$ bonds, the site expansion leads to a rotation of the tetrahedron with a di-trigonal angle locally increasing to $\sim-10^{\circ}$ and to $\sim-16^{\circ}$ for the $\mathrm{Al}^{3+}$ - and $\mathrm{Fe}^{3+}$-bearing system, respectively (Fig. 3). This increasingly negative value indicates a displacement of the basal oxygen atoms away from the octahedra of the same TO layer (Mellini, 1982). This displacement shortens the $\mathrm{H}$ bonds between the basal oxygen atoms of the tetrahedron and the three interlayer-OH groups belonging to the adjacent layer. Similar influence of tetrahedral substitutions on the H-bonding pattern of interlayer-OH groups was previously pointed out by Scholtzová and Smrčok (2005). The length of the three $\mathrm{OH}$ bonds pointing to the basal oxygens of the substituted tetrahedron increases to 0.973 and $0.976 \AA$ for the $\mathrm{Al}^{3+}$ - and $\mathrm{Fe}^{3+}$-bearing systems, respectively (Table 1). Due to the 3fold symmetry, the vibrational pattern involving these three interlayer-OH groups corresponds to an in-phase stretching mode at 3536 and $3602 \mathrm{~cm}^{-1}$ (Table 2) for the $\mathrm{Fe}^{3+}$ - and $\mathrm{Al}^{3+}$-bearing system, respectively, and two degenerate outof-phase stretching modes leading to weaker bands at a frequency $\sim 10 \mathrm{~cm}^{-1}$ lower. The in-phase stretching mode carries the intensity at 3541 and $3605 \mathrm{~cm}^{-1}$ in the corresponding theoretical absorption spectra (Fig. 1). In comparison, the 


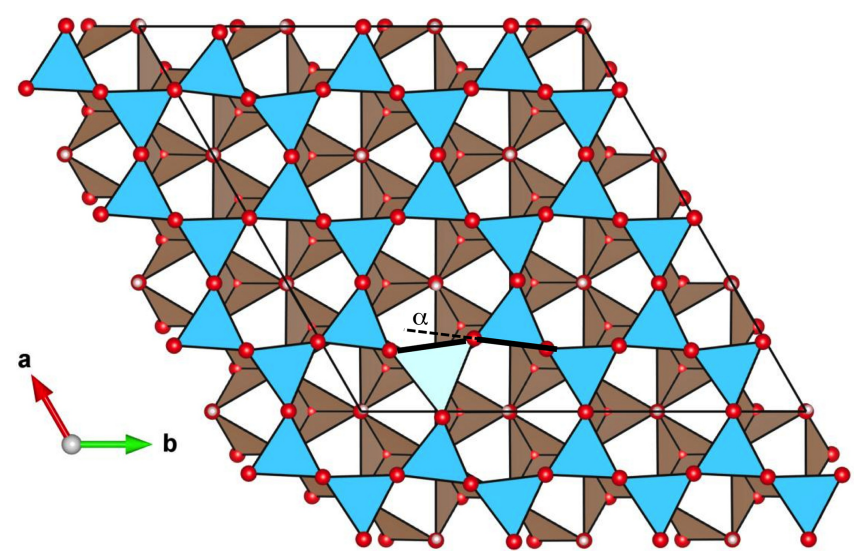

Figure 3. View of the structure of the $\left(\mathrm{Fe}^{3+}\right)_{\mathrm{T}}$ model along the [001] direction. Blue triangle: basal face of silicate tetrahedra; light blue triangle: basal face of the substituted site; red: oxygen atoms; light pink: $\mathrm{H}$ atoms; white and brown: faces of the $\mathrm{MgO}_{6}$ octahedra. The presence of the substituting cation induces a rotation of the tetrahedra moving the basal oxygens away from the octahedral sites, which corresponds to a local increase in the absolute value of the $\alpha$ angle. Structure drawing made with the VESTA software (Momma and Izumi, 2011).

neighboring inner-OH groups are less affected, with a moderate lengthening inducing a decrease in the $\mathrm{OH}$ stretching frequency of 14 and $9 \mathrm{~cm}^{-1}$ for the $\mathrm{Fe}^{3+}$ - and $\mathrm{Al}^{3+}$-bearing systems, respectively.

As could be anticipated from the distortion of the tetrahedral sheet, the presence of trivalent cations substituted for $\mathrm{Si}^{4+}$ cations significantly affects the $\mathrm{Si}-\mathrm{O}$ stretching modes involving the basal oxygen atoms and the related absorption bands (Fig. 2). The modes below $400 \mathrm{~cm}^{-1}$ are also strongly affected. In comparison, the $\mathrm{OH}$ libration and hindered translation are less modified.

\section{Discussion: interpretation of experimental lizardite spectra}

Theoretical spectra can be compared with previously reported experimental spectra of lizardite (Fig. 4), corresponding to a pure laboratory-grown sample (Mg_100; $x=0$ ) (Baron and Petit, 2016); a reference lizardite sample from Monte Fico, Elba (Viti and Mellini, 1997; Fuchs et al., 1998; Balan et al., 2002); and a lizardite sample from New Caledonia (Lz1) previously investigated by Fritsch et al. (2016, 2021). As attested by X-ray diffraction patterns, the crystalline quality is better in the two natural samples than in the synthetic one. The detailed chemical formula proposed for the Monte Fico lizardite is $\left(\mathrm{Mg}_{2.74} \mathrm{Fe}_{0.10}^{2+} \mathrm{Fe}_{0.05}^{3+} \mathrm{Al}_{0.11}\right)_{\Sigma=3.00}\left(\mathrm{Si}_{1.94} \mathrm{Al}_{0.05} \mathrm{Fe}_{0.01}^{3+}\right)_{\Sigma=2.00}$ $\mathrm{O}_{5.05}(\mathrm{OH})_{3.95}$ (Fuchs et al., 1998). Note that this lizardite has been shown to correspond to skeletal crystals with a minor proportion $(\sim 10 \%)$ of chrysotile and polygonal

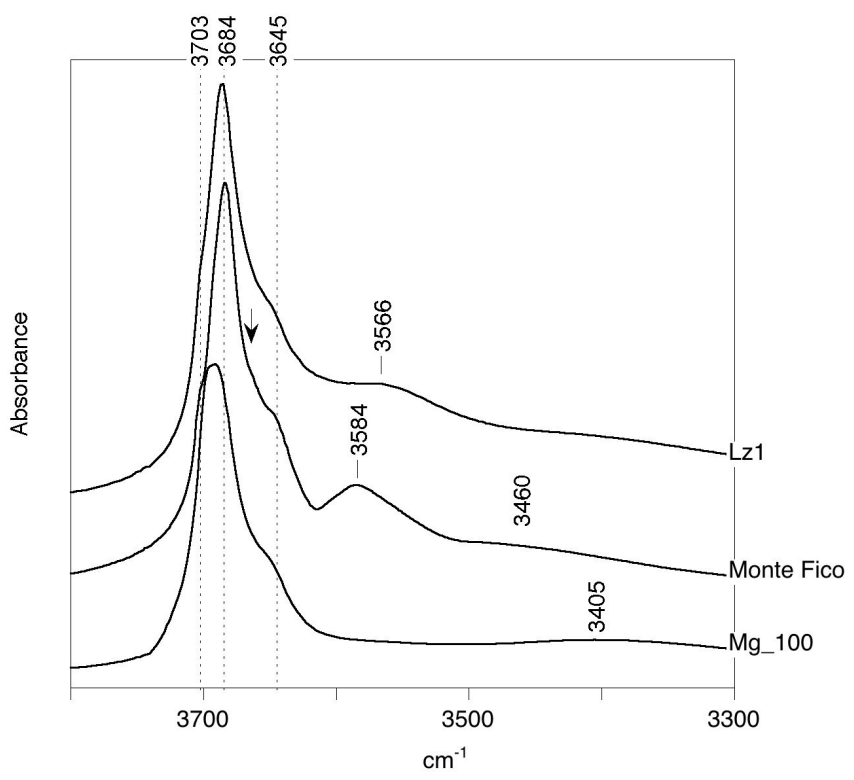

Figure 4. Experimental FTIR spectra of lizardite samples: New Caledonian Lz1 sample from Fritsch et al. (2021), Monte Fico sample from Balan et al. (2002) and laboratory-grown Mg_100 sample from Baron and Petit (2016). The arrow points to the shoulder at $\sim 3664 \mathrm{~cm}^{-1}$ in the spectrum of the Monte Fico sample.

serpentine (Capitani et al., 2021). The chemical composition of the Lz1 lizardite corresponds to the formula $\left(\mathrm{Mg}_{2.76} \mathrm{Fe}_{0.18} \mathrm{Ni}_{0.03} \mathrm{Cr}_{0.02}\right)_{\Sigma=2.99}\left(\mathrm{Si}_{1.99} \mathrm{Al}_{0.01}\right) \mathrm{O}_{5}(\mathrm{OH})_{4}$.

Compared to the Monte Fico lizardite, the Lz1 from New Caledonia is thus richer in iron and almost Al-free. It is noteworthy that a significant fraction of iron in this sample occurs under the trivalent state, as attested by $\mathrm{X}$-ray absorption spectroscopy investigations $\left(\mathrm{Fe}^{2+} / \mathrm{Fe}^{3+}=0.15\right.$; Farid Juillot, personal communication, 2021). Assuming that all iron ions are located in octahedral sites, this ratio leads to the formula $\left(\mathrm{Mg}_{2.76} \mathrm{Fe}_{0.02}^{2+} \mathrm{Fe}_{0.16}^{3+} \mathrm{Ni}_{0.03} \mathrm{Cr}_{0.02}\right)_{\Sigma=2.99}\left(\mathrm{Si}_{1.99} \mathrm{Al}_{0.01}\right) \mathrm{O}_{5}(\mathrm{OH})_{4}$. Accordingly, it is expected that the Lz1 lizardite spectrum displays specific features dominantly related to $\mathrm{Fe}^{3+}$, whereas the Monte Fico lizardite spectrum should reflect the dominant occurrence of $\mathrm{Al}^{3+}$ and octahedral $\mathrm{Fe}^{2+}$.

\subsection{Vibrational properties of lizardite in the $\mathrm{OH}$ stretching range}

The experimental FTIR spectra of lizardite display the signals previously interpreted in the light of the theoretical modeling of pure lizardite (Balan et al., 2002; Prencipe et al., 2009). They are ascribed to the inner-OH stretching at $3703 \mathrm{~cm}^{-1}$ and to the in-phase ( $\mathrm{A}_{1}$ symmetry) and out-ofphase (E symmetry) stretching of interlayer-OH groups at 3684 and $3645 \mathrm{~cm}^{-1}$, respectively (Fig. 4). Note that the frequency of the stronger in-phase stretching band of the interlayer-OH groups can display some variability depending on the sample microstructure and experimental geometry. 
These variations are related to long-range macroscopic electrostatic interactions affecting the vibrational spectra of polar crystals and are commonly observed in the powder spectra of hydrous phyllosilicates (Farmer, 1998, 2000; Balan et al., 2001, 2002, 2005) and layered hydroxides (Balan et al., 2008). In the case of powder spectra recorded on samples with arbitrary particle shapes, the intense band can be observed at a frequency intermediate between the corresponding $\mathrm{TO}$ and $\mathrm{LO}$ mode frequencies, with a width similar to the LO-TO splitting. For more specific shapes, such as blocky or cubic particles, the spectra can display asymmetric bands with components close to the $\mathrm{LO}$ and $\mathrm{TO}$ frequencies that can manifest as shoulders or inflection points (Fuchs, 1975). In the case of lizardite, the main band observed in the infrared spectrum of a thin film has been decomposed in two components at 3669 and $3688 \mathrm{~cm}^{-1}$, accounting for its asymmetry (Trittschack et al., 2012). Similarly, a component is observed at $\sim 3664 \mathrm{~cm}^{-1}$ as a shoulder on the low-frequency side of the main band at $3684 \mathrm{~cm}^{-1}$ in the FTIR powder spectrum of the Monte Fico lizardite (Fig. 4). Manifestations of long-range electrostatic effects are also observed in the Raman spectra recorded on oriented single crystals (Farmer, 2000). As discussed by Farmer (2000) for the Raman spectrum of dickite, when the spectrum is recorded on a (001) section in a backscattering geometry, the exchanged wave vector is parallel to the [001] polarization of the inphase stretching mode of interlayer-OH groups, which enhances the signal at the higher LO frequency. In the case of lizardite, Compagnioni et al. (2021) reports a shift of the main band from $3688.5 \mathrm{~cm}^{-1}$ in the micro-Raman spectrum recorded on an isotropic lizardite section parallel to the (001) plane to $\sim 3678 \mathrm{~cm}^{-1}$ for measurements made on the perpendicular section. In this latter case, the main band appears asymmetric with a component at $\sim 3668-3670 \mathrm{~cm}^{-1}$ (average $3669 \mathrm{~cm}^{-1}$ ). Accordingly, the LO frequency of the in-phase stretching of interlayer-OH groups should be close to $\sim 3688 \mathrm{~cm}^{-1}$, whereas the component systematically observed at $\sim 3669 \mathrm{~cm}^{-1}$ would correspond to its TO counterpart. The related splitting is consistent with the theoretical LO-TO splitting, which is predicted to be in the $14-21 \mathrm{~cm}^{-1}$ range.

These interpretations enable a comparison of the experimental frequencies with their theoretical counterparts (Fig. 5). The comparison reveals an overestimation of the theoretical stretching frequencies of interlayer-OH groups amounting to $50 \mathrm{~cm}^{-1}$, which is consistent with the observations made on antigorite $\left(\sim 57 \mathrm{~cm}^{-1}\right.$, Balan et al., 2021b). It is also in the range expected from previous investigations on hydrous defects in oxides and silicates (Balan et al., 2020; Balan, 2020). The difference between theoretical and experimental frequencies results from the partial cancellation of two types of errors, one being due to the use of an approximate exchange-correlation functional, which tends to underestimate the vibrational frequencies, and the other to the use of the harmonic approximation, which artificially increases

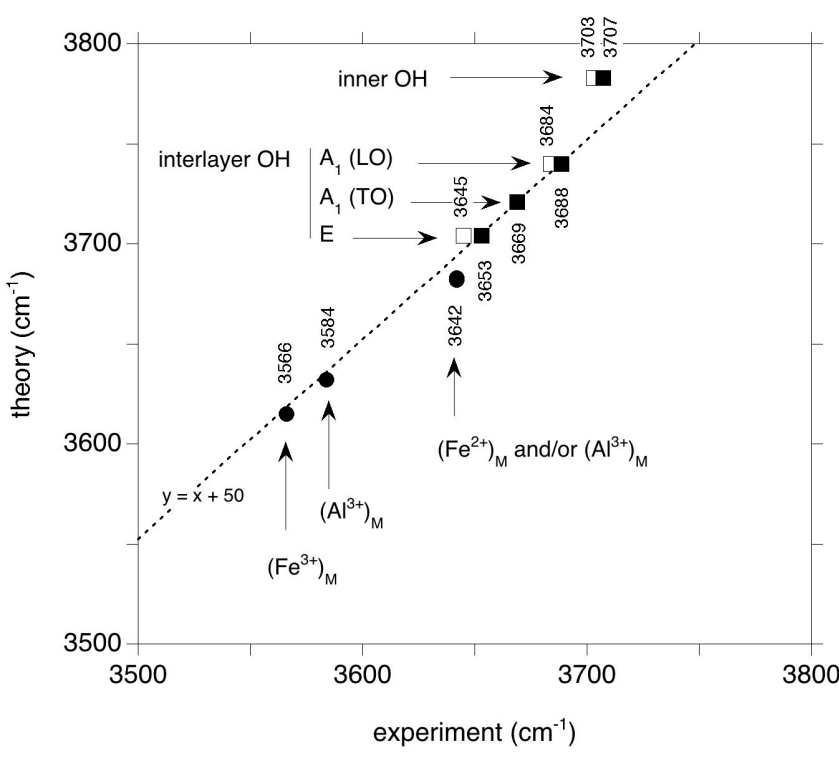

Figure 5. Relation between the theoretical frequencies (Fig. 1) and experimentally observed vibrational bands. Open squares: FTIR spectrum of Monte Fico lizardite (Balan et al., 2002); full squares: Raman frequencies of Monte Fico lizardite (Compagnoni et al., 2021). Black circles: signals ascribed to cationic impurities in the vibrational spectra of the Monte Fico and Lz1 lizardite. The average value of theoretical frequencies related to $\left(\mathrm{Fe}^{2+}\right)_{\mathrm{M}}\left(3683 \mathrm{~cm}^{-1}\right)$ almost coincides with the higher-frequency contributions related to $\mathrm{Al}^{3+}$ cations $\left(3682 \mathrm{~cm}^{-1}\right)$. The theoretical model overestimates the experimental stretching frequencies of interlayer-OH groups by $\sim 50 \mathrm{~cm}^{-1}$.

the $\mathrm{OH}$ stretching frequencies with respect to their anharmonic values (Balan et al., 2007). The theoretical correlation between bond length and $\mathrm{OH}$ frequencies (Tables 1 and 2) for the series of investigated models (Fig. 6) is also consistent with those previously determined at the same theoretical level on a series of hydroxylated defects in diopside and corundum (Balan et al., 2020; Balan, 2020). This relation between the vibrational frequency and a geometrical parameter rules out a contribution of the mass of the surrounding cations to the stretching dynamic of the $\mathrm{OH}$ groups, which is decoupled from the motion of other atoms.

\subsection{Vibrational signatures associated with cationic impurities in lizardite}

The $21 \mathrm{~cm}^{-1}$ downshift of the inner-OH stretching frequency induced by the presence of $\mathrm{Fe}^{2+}$ in its coordination sphere is similar to that determined at the same theoretical level for a $\mathrm{Ni}^{2+}$ for $\mathrm{Mg}^{2+}$ substitution in talc $\left(23 \mathrm{~cm}^{-1}\right.$, Blanchard et al., 2018). As in talc, the theoretical value however slightly overestimates the experimental observation. Based on the analysis of overtone bands in the near-infrared range (Balan et al., 2021a; Fritsch et al., 2021), the shift between $\mathrm{Mg}_{3}-\mathrm{OH}$ and $\mathrm{Mg}_{2} \mathrm{Fe}-\mathrm{OH}$ in lizardite $\left(16 \mathrm{~cm}^{-1}\right)$ is close to that deter- 


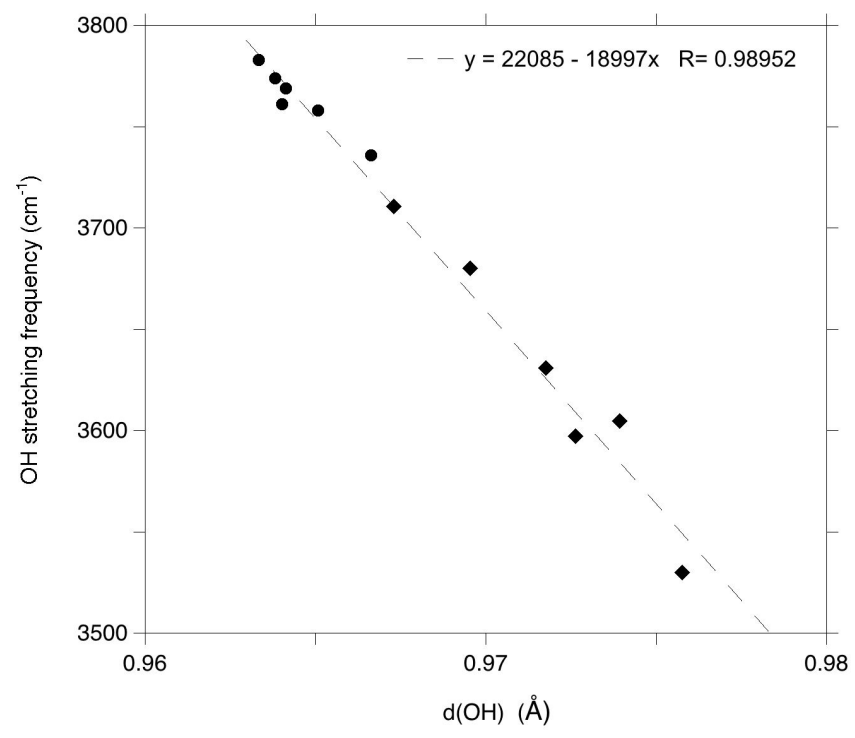

Figure 6. Relation between the theoretical stretching frequency (Table 2) and length (Table 1) of $\mathrm{OH}$ bonds in the lizardite models. For stretching modes displaying coupled $\mathrm{OH}$ contributions, the average values have been considered. Circles: inner-OH groups; diamonds: interlayer-OH groups.

mined in talc $\left(14 \mathrm{~cm}^{-1}\right.$, Petit et al., 2004). Accordingly, the inner-OH stretching band corresponding to a $\mathrm{Mg}_{2} \mathrm{Fe}^{2+}$ environment should occur at $\sim 3687 \mathrm{~cm}^{-1}$, overlapping with the strong band related to the in-phase interlayer-OH stretching band of lizardite.

The signal of interlayer-OH groups in a $\mathrm{Mg}_{2} \mathrm{Fe}^{2+}$ environment is theoretically determined at a frequency $\sim 20 \mathrm{~cm}^{-1}$ lower than that of the out-of-phase stretching of interlayer $\mathrm{OH}$ in a $\mathrm{Mg}_{3}$ environment (Fig. 1). However, its contribution is not resolved in the experimental FTIR spectra (Fig. 4) and should mostly contribute to the broadening of the out-ofphase (E symmetry) stretching band identified at $3645 \mathrm{~cm}^{-1}$. Interestingly, the micro-Raman spectrum of lizardite reported by Compagnoni et al. (2021) reveals the occurrence of two components with different polarization properties at $\sim 3653$ and $\sim 3642 \mathrm{~cm}^{-1}$. The relative intensity of the component at $\sim 3653 \mathrm{~cm}^{-1}$ is enhanced in the spectrum recorded on an isotropic section parallel to the (001) plane. Based on the comparison with the theoretical frequencies, this component could correspond to the out-of-phase stretching band of pure lizardite, whereas that determined at $\sim 3642 \mathrm{~cm}^{-1}$ could be ascribed to the stretching of interlayer- $\mathrm{OH}$ groups in a $\mathrm{Mg}_{2} \mathrm{Fe}^{2+}$ environment (Fig. 5). It is noteworthy that the splitting of the bands associated with the substituted site is relatively weak $\left(8 \mathrm{~cm}^{-1}\right.$, Fig. 1$)$, potentially leading to the experimental observation of a single band at the average frequency. However, a contribution of trivalent cations (mostly octahedrally coordinated $\mathrm{Al}^{3+}$ in the Monte Fico sample) cannot be excluded as they lead to theoretical absorption signals at similar frequencies (Fig. 1).
Assuming that a difference between experimental and theoretical frequencies close to $50 \mathrm{~cm}^{-1}$ is also valid for the interlayer- $\mathrm{OH}$ groups in $\mathrm{Al}^{3+}$ - and $\mathrm{Fe}^{3+}$-bearing models, the bands respectively observed at 3584 and $3568 \mathrm{~cm}^{-1}$ in the Monte Fico and Lz1 samples (Fig. 4) are most likely associated with the occurrence of trivalent cations. Consistently, this type of signal is lacking in the laboratory-grown pure lizardite sample. The shift of the band observed between the Monte Fico and Lz1 samples is also consistent with the respective predominance of octahedrally coordinated $\mathrm{Al}^{3+}$ and $\mathrm{Fe}^{3+}$ in these samples (Fig. 5).

It is however challenging to discriminate the occurrence of octahedral or tetrahedral $\mathrm{Al}^{3+}$. Despite a difference in the associated stretching frequencies amounting to $27 \mathrm{~cm}^{-1}$, both could contribute to the broad signal centered at $3584 \mathrm{~cm}^{-1}$ (half width at half maximum of $\sim 35 \mathrm{~cm}^{-1}$ ). The contribution related to tetrahedral $\mathrm{Fe}^{3+}$ is expected at a frequency $75 \mathrm{~cm}^{-1}$ lower than that associated with octahedral $\mathrm{Fe}^{3+}$, corresponding to an expected experimental frequency of $\sim 3490 \mathrm{~cm}^{-1}$. The absence of such a signal suggests that the concentration of tetrahedral $\mathrm{Fe}^{3+}$ is too low to be detected in the samples. Additional features can also complicate the identification of bands related to trivalent cations at tetrahedral sites. The expected signal likely overlaps with the broad absorption by water molecules adsorbed at the surface of the particles, which is centered at $3405 \mathrm{~cm}^{-1}$ in the pure and finely divided synthetic lizardite sample (Fig. 4). Moreover, the frequency of the interlayer-OH stretching bands appears to be controlled by the perturbation of the silicate sheet geometry, which affects the H-bonding pattern. Recalling that the present theoretical models correspond to a perfectly ordered cationic distribution because of the periodic boundary conditions, they are expected to only provide a local description of the changes induced by the presence of the impurity. The more random cationic ordering occurring in experimental samples likely induces a distribution of the tetrahedra rotation angles and of the related H-bond lengths, causing a broadening of the $\mathrm{OH}$ stretching signal.

To this respect, the occurrence of tetrahedral trivalent cations should efficiently contribute to the broadening of the whole vibrational properties of lizardite, not only affecting the stretching modes of interlayer-OH groups but also the other vibrational modes observed in the mid-IR range. In comparison, low concentration of cations at octahedral sites should have a more local effect and weaker broadening efficiency. It is however noteworthy that higher substitution levels of divalent or trivalent cations can also lead to a significant broadening due to the combined effect of the induced structural strain and increasing variability of cationic configurations, which include the electrostatically favored coupled substitution of trivalent cations at both $\mathrm{M}$ and $\mathrm{T}$ sites (e.g. Yariv and Heller-Kallai, 1973; Serna et al., 1979; Velde, 1980; Baron and Petit, 2016). 
Data availability. PWscf and PHonon codes (Giannozzi et al., 2009) are available at http://www.quantum-espresso.org/ (last access: 21 September 2021). The pseudo-potentials are available at http://www.quantum-simulation.org/potentials/sg15_oncv/ (last access: 21 September 2021, Schlipf and Gigy, 2015). Specific requests should be addressed to Etienne Balan (etienne.balan@sorbonneuniversite.fr).

Author contributions. EB, GR and LP performed the calculations. All co-authors contributed to the discussion of the results and preparation of the manuscript.

Competing interests. Some authors are members of the editorial board of European Journal of Mineralogy. The peer-review process was guided by an independent editor, and the authors have also no other competing interests to declare.

Disclaimer. Publisher's note: Copernicus Publications remains neutral with regard to jurisdictional claims in published maps and institutional affiliations.

Acknowledgements. We thank Georgios Chryssikos and one anonymous reviewer for their insightful comments. This research is an outcome of the projects "Conditions of formation of $\mathrm{Mg} / \mathrm{Ni}$ silicate ores from New Caledonia" (2010, CNRS INSU CESSUR) and "Ni/Co mineralization factors of laterites derived from ultramafic rocks of New-Caledonia" (2010-2014, CNRT Nickel and its environment). Calculations have been performed using the computing resources of IMPMC (Sorbonne Universite-CNRS-MNHN) and the HPC resources of IDRIS under the allocation 2020-A0080910820 attributed by GENCI (Grand Équipement National de Calcul Intensif).

Review statement. This paper was edited by Tiziana Boffa Ballaran and reviewed by two anonymous referees.

\section{References}

Adebayo, G. A., Zhanabergenov, Zh., Ernazarov, U., Badmus, B. S., and Anusionwu, B. C.: First principles study of electronic structure, structural and optical properties of $\mathrm{Mg}_{3} \mathrm{Si}_{2} \mathrm{O}_{5}(\mathrm{OH})_{4}$, Appl. Clay Sci., 93-94, 8-11, https://doi.org/10.1016/j.clay.2014.03.003, 2014.

Bailey, S. W.: Odinite, a new dioctahedral-trioctahedral $\mathrm{Fe}^{3+}$-rich 1:1 clay mineral, Clay Minerals, 23, 237-247, https://doi.org/10.1180/claymin.1988.023.3.01, 1988.

Balan, E.: Theoretical infrared spectra of $\mathrm{OH}$ defects in corundum $\left(\alpha-\mathrm{Al}_{2} \mathrm{O}_{3}\right)$, Eur. J. Mineral., 32, 457-467, https://doi.org/10.5194/ejm-32-457-2020, 2020.

Balan, E., Saitta, A. M., Mauri, F., and Calas, G.: First-principles modeling of the infrared spectrum of kaolinite, Am. Mineral., 86, 1321-1330, https://doi.org/10.2138/am-2001-11-1201, 2001.
Balan, E., Saitta, A. M., Mauri, F., Lemaire, C., and Guyot, F.: First-principles calculation of the infrared spectrum of lizardite, Am. Mineral., 87, 1286-1290, https://doi.org/10.2138/am-20021003, 2002.

Balan, E., Lazzeri, M., Saitta, A. M., Allard, T., Fuchs, Y., and Mauri, F.: First-principles study of $\mathrm{OH}$ stretching modes in kaolinite, dickite and nacrite, Am. Mineral., 90, 50-60, https://doi.org/10.2138/am.2005.1675, 2005.

Balan, E., Lazzeri, M., Delattre, S., Meheut, M., Refson, K., and Winkler, B.: Anharmonicity of inner-OH stretching modes in hydrous phyllosilicates: assessment from first-principles frozen-phonon calculations, Phys. Chem. Miner., 34, 621-625, https://doi.org/10.1007/s00269-007-0176-4, 2007.

Balan, E., Blanchard, M., Hochepied, J.-F., and Lazzeri, M.: Surface modes in the infrared spectrum of hydrous minerals: the $\mathrm{OH}$ stretching modes of bayerite, Phys. Chem. Miner., 35, 279-285, https://doi.org/10.1007/s00269-008-0221-y, 2008.

Balan, E., Paulatto, L., Liu, J., and Ingrin, J.: Low-temperature infrared spectrum and atomic-scale structure of hydrous defects in diopside, Eur. J. Mineral., 32, 505-520, https://doi.org/10.5194/ejm-32-505-2020, 2020.

Balan, E., Fritsch, E., Juillot, F., Allard, T., and Petit, S.: Local mode interpretation of the $\mathrm{OH}$ overtone spectrum of 1:1 phyllosilicates, Eur. J. Mineral., 33, 209-220, https://doi.org/10.5194/ejm-33209-2021, 2021a.

Balan, E., Fritsch, E., Radtke, G., Paulatto, L., Juillot, F., and Petit, S.: First-principles modeling of the infrared spectrum of antigorite, Eur. J. Mineral., 33, 389-400, https://doi.org/10.5194/ejm33-389-2021, 2021b.

Baron, F. and Petit, S.: Interpretation of the infrared spectra of the lizardite-nepouite series in the near and middle infrared range, Am. Mineral., 101, 423-430, https://doi.org/10.2138/am-20165352, 2016.

Baroni, S., de Gironcoli, S., Dal Corso, A., and Giannozzi, P.: Phonons and related crystal properties from densityfunctional perturbation theory, Rev. Mod. Physics, 73, 515-561, https://doi.org/10.1103/RevModPhys.73.515, 2001.

Blanchard, M., Méheut, M., Delon, L., Poirier, M., Micoud, P., Le Roux, C., and Martin, F.: Infrared spectroscopic study of the synthetic Mg-Ni talc series, Phys. Chem. Miner., 45, 843-854, https://doi.org/10.1007/s00269-018-0966-x, 2018.

Brindley, G. W., Chih-chun Kao, Harrison, J. L., Lipsicas, M., and Raythatha, R.: Relation between structural disorder and other characteristics of kaolinites and dickites, Clays Clay Miner., 34 239-249, https://doi.org/10.1346/CCMN.1986.0340303, 1986.

Capitani, G., Compagnoni, R., Cossio, R., Botta, S., and Mellini, M.: The intracrystalline microstructure of Monte Fico lizardite, by optics, $\mu$-Raman spectroscopy and TEM, Eur. J. Mineral., 33, 425-432, https://doi.org/10.5194/ejm-33-425-2021, 2021.

Compagnoni, R, Cossio, R., and Mellini, M.: Raman anisotropy in serpentine minerals, with a caveat on identification, J. Raman Spectrosc., 52, 1334-1345, https://doi.org/10.1002/jrs.6128, 2021.

Farmer, V. C.: The infrared spectra of minerals, Mineralogical Society Monograph, Mineralogical Society, London, https://doi.org/10.1180/mono-4, 1974.

Farmer, V. C.: Differing effect of particle size and shape in the infrared and Raman spectra of kaolinite, Clay Miner., 33, 601-604, https://doi.org/10.1180/000985598545921, 1998. 
Farmer, V. C.: Transverse and longitudinal crystal modes associated with $\mathrm{OH}$ stretching vibrations in single crystals of kaolinite and dickite, Spectrochim. Acta A, 56, 927-930, https://doi.org/10.1016/S1386-1425(99)00182-1, 2000.

Fialips, C.-I., Navrotsky, A., and Petit, S.: Crystal properties and energetics of synthetic kaolinite, Am. Mineral., 86, 304-311, https://doi.org/10.2138/am-2001-2-313, 2001.

Fritsch, E., Juillot, F., Dublet, G., Fonteneau, L, Fandeur, D., Martin, E., Caner, L. Auzende A.-L., Grauby, O., and Beaufort, D.: An alternative model for the formation of hydrous $\mathrm{Mg} / \mathrm{Ni}$ layer silicates ("deweylite"/"garnierite") in faulted peridotites of New Caledonia: I. Texture and mineralogy of a paragenetic succession of silicate infillings, Eur. J. Mineral., 28, 295-311, https://doi.org/10.1127/ejm/2015/0027-2503, 2016.

Fritsch, E., Balan, E., Petit, S., and Juillot, F.: Structural, textural, and chemical controls on the $\mathrm{OH}$ stretching vibrations in serpentine-group minerals, Eur. J. Mineral., 33, 447-462, https://doi.org/10.5194/ejm-33-447-2021, 2021.

Fuchs, R.: Theory of the optical properties of ionic crystal cubes, Phys Rev B, 11, 1732-1740, https://doi.org/10.1103/PhysRevB.11.1732, 1975.

Fuchs, Y., Linares, J., and Mellini, M.: Mössbauer and infrared spectrometry of lizardite-1T from Monte Fico, Elba, Phys. Chem. Miner., 26, 111-115, https://doi.org/10.1007/s002690050167, 1998.

Ghaderi, N., Zhang, H., and Sun, T.: Relative stability and contrasting elastic properties of serpentine polymorphs from firstprinciples calculations, J. Geophys. Res.-Sol. Ea., 120, 48314842, https://doi.org/10.1002/2015JB012148, 2015.

Giannozzi, P., Baroni, S., Bonini, N., Calandra, M., Car, R., Cavazzoni, C., Ceresoli, D., Chiarotti, G. L., Cococcioni, M., Dabo, I., Dal Corso, A., de Gironcoli, S., Fabris, S., Fratesi, G., Gebauer, R., Gerstmann, U., Gougoussis, C., Kokalj, A., Lazzeri, M., Martin-Samos, L., Marzari, N., Mauri, F., Mazzarello, R., Paolini, S., Pasquarello, A., Paulatto, L., Sbraccia, C., Scandolo, S., Sclauzero, G., Seitsonen, A. P., Smogunov, A., Umari, P., and Wentzcovitch, R. M.: Quantum ESPRESSO: a modular and open-source software project for quantum simulations of materials, J. Phys. Cond. Mat., 21, 395502, https://doi.org/10.1088/0953-8984/21/39/395502, 2009.

Gregorkiewitz, M., Lebech, B., Mellini, M., and Viti, C.: Hydrogen positions and thermal expansion in lizardite-1 $T$ from Elba: A low-temperature study us- ing Rietveld refinement of neutron diffraction data, Am. Mineral., 81, 1111-1116, https://doi.org/10.2138/am-1996-9-1008, 1996.

Hamann, D. R.: Optimized norm-conserving Vanderbilt pseudopotentials, Phys. Rev. B, 88, 085117, https://doi.org/10.1103/PhysRevB.88.085117, 2013.

Hermansson, K.: Ab initio calculations of the fundamental $\mathrm{OH}$ frequency of bound $\mathrm{OH}-$ ions, J. Chem. Phys., 95, 3578, https://doi.org/10.1063/1.460808, 1991.

Hossain, F. M., Dlugogorski, B. Z., Kennedy, E. M., Belova, I. V., and Murch, G. E.: Ab-initio electronic structure, optical, dielectric and bonding properties of lizardite-1T, Comput. Mater. Sci., 50, 1725-1730, https://doi.org/10.1016/j.commatsci.2011.01.003, 2011.

Johnston, C. T., Wang, S. L., Bish, D. L., Dera, P., Agnew, S. F., and Kenney III, J. W.: Novel pressure induced phase transformations in hydrous layered materials: a comparative single crystal high pressure Raman/XRD study of dickite and gibbsite, Geophys. Res. Lett., 29, 1029, https://doi.org/10.1029/2002GL015402, 2002.

Kendrick, J. and Burnett, A. D.: PDielec: The calculation of infrared and terahertz absorption for powdered crystals, J. Comput. Chem., 37, 1491-1504, https://doi.org/10.1002/jcc.24344, 2016.

Lacinska, A. M., Styles, M. T., Bateman, K., Wagner, D., Hall, M. R., Gowing, C., and Brown, P. D.: Acid-dissolution of antigorite, chrysotile and lizardite for ex situ carbon capture and storage by mineralisation, Chem. Geol., 437, 153-169, https://doi.org/10.1016/j.chemgeo.2016.05.015, 2016.

Leslie, M. and Gillan, M. J.: The energy and elastic dipole tensor of defects in ionic crystals calculated by the supercell method, J. Phys. Chem., 18, 973-982, https://doi.org/10.1088/00223719/18/5/005, 1985.

Libowitzky, E.: Correlation of $\mathrm{O}-\mathrm{H}$ stretching frequencies and $\mathrm{O}-$ $\mathrm{H} \cdot \cdot \mathrm{O}$ hydrogen bond lengths in minerals, Mh. Chemie, 130, 1047-1059, https://doi.org/10.1007/BF03354882, 1999.

Mellini, M.: The crystal structure of lizardite- $1 T$ : hydrogen bonds and polytypism, Am. Mineral., 67, 587-598, 1982.

Momma, K. and Izumi, F.: VESTA 3 for three-dimensional visualization of crystal, volu- metric and morphology data, J. Appl. Crystallogr., 44, 1272-1276, https://doi.org/10.1107/S0021889811038970, 2011.

Perdew, J. P., Burke, K., and Ernzerhof, M.: Generalized Gradient Approximation Made Simple, Phys. Rev. Lett., 77, 3865-3868, https://doi.org/10.1103/PhysRevLett.77.3865, 1996.

Petit, S., Martin, F., Wiewiora, A., De Parseval, P., and Decarreau, A.: Crystal-chemistry of talc: a near infrared (NIR) spectroscopy study, Am. Mineral., 89, 319-326, https://doi.org/10.2138/am2004-2-310, 2004.

Prencipe, M., Noel, Y., Bruno, M., and Dovesi, R.: The vibrational spectrum of lizardite- $1 T\left[\mathrm{Mg}_{3} \mathrm{Si}_{2} \mathrm{O}_{5}(\mathrm{OH})_{4}\right]$ at the $\Gamma$ point: A contribution from an ab initio B3LYP calculation, Am. Mineral., 94, 986-994, https://doi.org/10.2138/am.2009.3127, 2009.

Prost, R., Damene, A., Huard, E., Driard, J., and Leydecker, J. P.: Infrared study of structural $\mathrm{OH}$ in kaolinite, dickite, nacrite and poorly crystalline kaolinite at 5 to $600 \mathrm{~K}$, Clays Clay Miner., 37, 464-468, https://doi.org/10.1346/CCMN.1989.0370511, 1989.

Salje, E. K. H.: Hard mode spectroscopy: Experimental studies of structural phase transitions, Phase Transitions, 37, 83-110, https://doi.org/10.1080/01411599208222888, 1992.

Schlipf, M. and Gygi, F.: Optimization algorithm for the generation of ONCV pseudopotentials, Comput. Phys. Comm., 196, 36-44, https://doi.org/10.1016/j.cpc.2015.05.011, 2015.

Scholtzová, E. and Smrčok, L.: On local structural changes in lizardite-1T: $\left\{\mathrm{Si}^{4+} / \mathrm{Al}^{3+}\right\}, \quad\left\{\mathrm{Si}^{4+} / \mathrm{Fe}^{3+}\right\}, \quad\left[\mathrm{Mg}^{2+} / \mathrm{Al}^{3+}\right]$, $\left[\mathrm{Mg}^{2+} / \mathrm{Fe}^{3+}\right]$ substitutions, Phys. Chem. Miner., 32, 362-373, https://doi.org/10.1007/s00269-005-0006-5, 2005.

Serna, C. J., White, J. L., and Velde, B. D.: The effect of aluminum on the infrared spectra of $7 \AA$ trioctahedral minerals, Mineral. Mag., 43, 141-148, https://doi.org/10.1180/minmag.1979.043.325.14, 1979.

Shannon, R. D.: Revised effective ionic radii and systematic studies of interatomic distances in halides and chalcogenides, Acta Cryst., A32, 751-767, https://doi.org/10.1107/S0567739476001551, 1976.

Szalay, V., Kovaìcs, L., Wöhlecke, M., and Libowitzky, E.: Stretching potential and equilibrium length of the $\mathrm{OH}$ bonds in solids, 
Chem. Phys. Lett., 354, 56-61, https://doi.org/10.1016/S00092614(02)00099-4, 2002.

Trittschack, R., Grobéty, B., and Koch-Müller, M.: In situ hightemperature Raman and FTIR spectroscopy of the phase transformation of lizardite, Am. Mineral., 97, 1965-1976, https://doi.org/10.2138/am.2012.4162, 2012.

Tunega, D., Bučko, T., and Zaoui, A.: Assessment of ten DFT methods in predicting structures of sheet silicates: Importance of dispersion corrections, J. Chem. Phys., 137, 114105, https://doi.org/10.1063/1.4752196, 2012.

Velde, B.: Ordering in synthetic aluminous serpentines; infrared spectra and cell dimensions, Phys. Chem. Miner., 6, 209-220, https://doi.org/10.1007/BF00309857, 1980.

Viti, C. and Mellini, M.: Contrasting chemical compositions in associated lizardite and chrysotile in veins from Elba, Italy, Eur. J. Mineral., 9, 585-596, https://doi.org/10.1127/ejm/9/3/0585, 1997.
Welch, M., Montgomery, W., Balan, E., and Lerch P.: Insights into the high-pressure behavior of kaolinite from infrared spectroscopy and quantum-mechanical calculations, Phys. Chem. Miner., 39, 143-151, https://doi.org/10.1007/s00269-011-0469$5,2012$.

Wicks, F. J. and O'Hanley, D. S.: Serpentine minerals: structures and petrology, in: Hydrous phyllosilicates, edited by: Bailey, S., Mineralogical Society of America, Rev. Mineral., 19, 91-167, 1988.

Yariv, S. and Heller-Kallai, L.: The relationship between the I.R. spectra of serpentines and their structures, Clays Clay Miner., 23, 145-152, https://doi.org/10.1346/CCMN.1975.0230210, 1975. 